\title{
False in Name Only-Gastroduodenal Artery Pseudoaneurysm in a Recurrently Bleeding Patient: Case Report and Literature Review.
}

\author{
M. Binetti \\ St. Orsola University Hospital
}

A. Lauro

St. Orsola University Hospital

R. Golfieri

St. Orsola University Hospital

S Vaccari

St. Orsola University Hospital.

Yoplowntresa and additional works at: https://jdc.jefferson.edu/surgeryfp Ilmberto I Hospital

Part of the Surgery Commons

\section{$\frac{\text { Let us know how access to this document benefits you }}{\text { See next page for additional authors }}$}

\section{Recommended Citation}

Binetti, M.; Lauro, A.; Golfieri, R.; Vaccari, S; D'Andrea, V; Marino, I. R.; Cervellera, M.; Renzulli, M.; and Tonini, V., "False in Name Only-Gastroduodenal Artery Pseudoaneurysm in a Recurrently Bleeding Patient: Case Report and Literature Review." (2019). Department of Surgery Faculty Papers. Paper 175.

https://jdc.jefferson.edu/surgeryfp/175

This Article is brought to you for free and open access by the Jefferson Digital Commons. The Jefferson Digital Commons is a service of Thomas Jefferson University's Center for Teaching and Learning (CTL). The Commons is a showcase for Jefferson books and journals, peer-reviewed scholarly publications, unique historical collections from the University archives, and teaching tools. The Jefferson Digital Commons allows researchers and interested readers anywhere in the world to learn about and keep up to date with Jefferson scholarship. This article has been accepted for inclusion in Department of Surgery Faculty Papers by an authorized administrator of the Jefferson Digital Commons. For more information, please contact: JeffersonDigitalCommons@jefferson.edu. 


\section{Authors}

M. Binetti, A. Lauro, R. Golfieri, S Vaccari, V D'Andrea, I. R. Marino, M. Cervellera, M. Renzulli, and V. Tonini 
False in Name Only - Gastroduodenal artery pseudoaneurysm in a recurrently bleeding patient: case report and literature review

Binetti M. ${ }^{1}$, Lauro A. ${ }^{1}$, Golfieri R. ${ }^{2}$, Vaccari S. ${ }^{1}$, D’Andrea V. ${ }^{3}$, Marino I.R. ${ }^{4}$, Cervellera M. ${ }^{1}$, Renzulli M. ${ }^{2 \S}$

$$
\text { and Tonini V. }{ }^{1 \S}
$$

\section{Affiliations:}

1. Emergency Surgery Department- St. Orsola University Hospital- Bologna (ITALY)

2. Radiology Unit, Department of Experimental- Diagnostic and Speciality Medicine, St. Orsola University Hospital, Bologna (ITALY)

3. Department of Surgical Sciences - La Sapienza University -Umberto I Hospital- Rome (ITALY)

4. Sidney Kimmel Medical College, Thomas Jefferson University- Philadelphia, PA (USA)

$\S$ Renzulli M. and Tonini V. equally contributed as joint senior Authors.

Corresponding author:

Professore Augusto Lauro

augustola@yahoo.com

\section{Abbreviations :}

ALT Alanine Aminotransferase

AST Aspartate Aminotransferase

bpm beats per minute

C-RP C-reactive protein

EGD Esophagogastric-duodenal endoscopy

GI Gastrointestinal

GDA Gastroduodenal artery

Hbg Hæmoglobin

IV Intravenous

NG Nasogastric

WBC White Blood Cell count

COPD Chronic obstructive pulmonary disease

PLT Platelet count

Conflict of interest $=$ none of the authors have any conflicts of interest pertaining to this work. 


\section{Abstract (85 words):}

INTRODUCTION: Although the diagnosis of visceral pseudoaneurysm is unusual, it requires emergent attention due to the risk of rupture. We describe a 70-year old man with a gastroduodenal artery (GDA) pseudoaneurysm manifest as recurrent hæmorrhage.

AREAS COVERED: We highlight the possible ætiologies, clinical presentations, diagnostic tools and treatment options for this condition. In this instance, the patient was successfully treated by selective angio-embolization.

EXPERT COMMENTARY: A visceral pseudoaneurysm should be considered in patients with abdominal pain and GI hæmorrhage. At present, angio-embolization is first-line therapy.

\section{Keywords:}

Recurrent bleeding, gastroduodenal artery, pseudoaneurysm, angio-embolization

\section{Case report and evolution:}

A 70-year old man was admitted on May, 2019 to the Sant' Orsola University Hospital Emergency Department due to rectal bleeding. On admission, his blood pressure was $160 / 85 \mathrm{mmHg}$, pulse rate $123 \mathrm{bpm}, \mathrm{SpO}_{2} 94 \%$ breathing room air, temperature $37^{\circ} \mathrm{C}$. Clinical evaluation revealed a benign abdominal exam without signs of peritonitis; rectal evaluation revealed traces of blood. Past medical history was notable for active smoking and alcoholism, asthma complicated by COPD, and previous rib fractures.

Admission blood tests included: Hgb $12.2 \mathrm{~g} / \mathrm{dL}$, Plt 321,000/ $\mathrm{mm}^{3}$, INR 1.10, aPTT ratio 0.86, WBC $19,240 / \mathrm{mm}^{3}$, urea $100 \mathrm{mg} / \mathrm{dL}$, creatinine $0.67 \mathrm{mg} / \mathrm{dL}$, sodium $137 \mathrm{mmol} / \mathrm{L}$, potassium $4.4 \mathrm{mmol} / \mathrm{L}$, total bilirubin $0.84 \mathrm{mg} / \mathrm{dL}$, AST $23 \mathrm{U} / \mathrm{L}$, ALT $32 \mathrm{U} / \mathrm{L}$, amylase $108 \mathrm{U} / \mathrm{L}$ and C-RP $0.60 \mathrm{mg} / \mathrm{dL}$. Abdominal X-rays showed gastric dilation without distension of the abdominal loops and without free air. Initial treatment was conservative with NG tube insertion and IV pantoprazole. Further blood tests showed a drop in hæmoglobin level $(11.3 \mathrm{~g} / \mathrm{dL})$. The patient was admitted to the Medicine Department.

An EGD was performed: a deep, anterior duodenal bulb ulcer was seen (15-20 mm) with fibrinous aspect and stigmata of previous bleeding (Figure 1). In the $2^{\text {nd }}$ part of the duodenum, there were 
superficial erosions; next to the Z-line a little single erosion ( $4 \mathrm{~mm}$ ) was discovered. During the next 12 hours, control blood tests showed a progressive decrease in hæmoglobin level: $10.5 \mathrm{~g} / \mathrm{dL}$ and then 8.1 g/dL. An emergency EGD was repeated: in the gastric lumen there was abundant blood without lesions, whereas active bleeding was observed from a duodenal ulcer covered by a clot. Epinephrine treatment of the lesion margins was performed followed by the transfusion of $2 \mathrm{U}$ of blood.

The day after, another emergency EGD was performed for further rectal bleeding associated with hypotension. Treatment with epinephrine plus Hemospray ${ }^{\mathrm{TM}}$ was performed. A few hours later, further episodes of rectal bleeding occurred. The patient was admitted to the Emergency Surgery Unit and an exploratory laparotomy was carried out. A $3 \times 3 \mathrm{~cm}$ mass in the $2^{\text {nd }}$ portion of the duodenum, indissociable from the hepatic peduncle, was identified. A gastrotomy showed the stomach lumen full of coagulated blood. Hæmostasis was achieved by suturing the duodenal ulcer adding fibrin glue. Another seven blood units were transfused. The patient was transferred to the Intensive Care Unit. After three days, the patient was admitted again to Emergency Surgery Unit where, the same day, a new episode of rectal bleeding recurred. An abdominal CT scan documented a $16 \mathrm{~mm}$ pseudoaneurysm of the gastroduodenal artery without active bleeding, likely responsible of the recurrent intestinal bleeding (Figure 2). The patient was brought to the radiology suite where selective arteriography was performed. By placing the angiographic catheter in the common hepatic artery, the GDA was not visualized due to a blood flow reversal in this vessel caused by the stenosis of the celiac trunk. Since the lesion was documented when the tip of the catheter was positioned in the GDA proximal to the origin of the pseudoaneurysm, the GDA was embolized by using micro-coils positioned proximal and distal to the origin of the pseudoaneurysm. After the embolization, an angiographic study was used to positioning the catheter in the superior mesenteric artery. During this check, a small branch of the inferior pancreatic-duodenal arch feeding the pseudoaneurysm was identified. Nevertheless, this artery was smaller than the calibre of the microcatheter (2.4 F) and, therefore it was not possible to catheterize this vessel in order to perform a selective embolization with standard techniques. Finally, considering the hæmodynamic instability of the patient and the number of episodes of recurrent bleeding, a decision was taken to dissect this small branch by using the microguide and the micro-catheter. Definitive angiographic control after the dissection demonstrated the complete exclusion of the pseudoaneurysm from the circulation, with the patency of the remaining 
pancreatic-duodenal arteries (Figure 3). In the following days, no recurrent bleeding occurred. The patient was hæmodynamically stable and was finally re-transferred to the Medicine Department. The patient was discharged in good clinical conditions 15 days after the angio-embolization procedure. An abdominal CT scan, performed 2 weeks after discharge, confirmed the complete absence of the pseudoaneurysm, with no signs of duodenal wall ischemia (Figure 4).
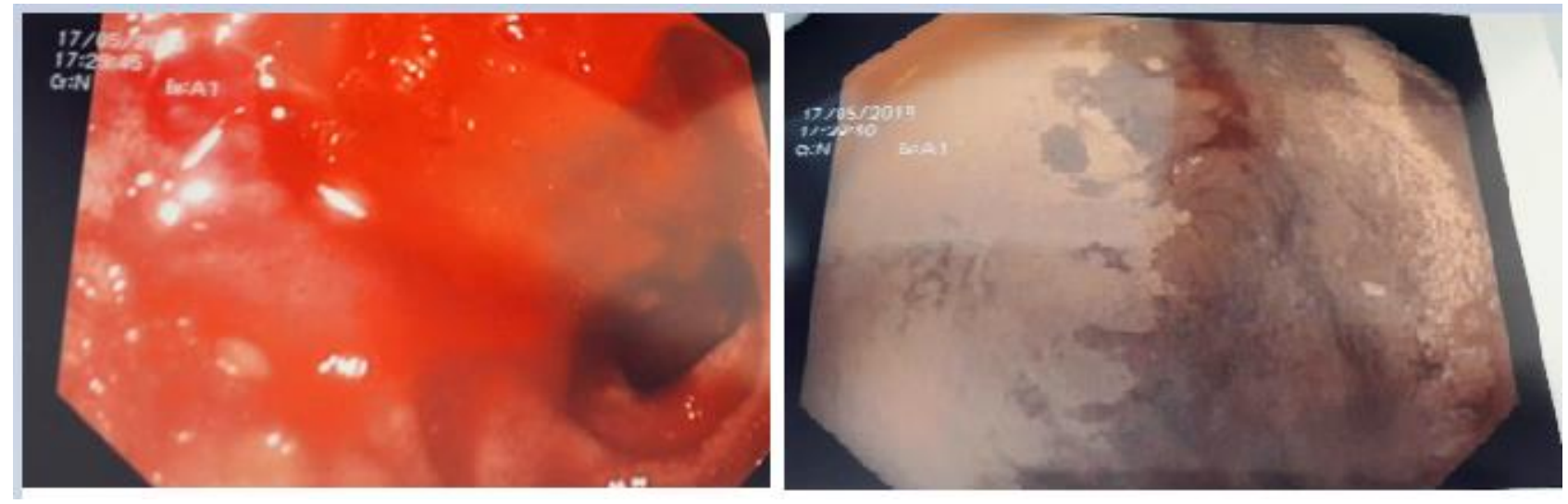

a. gastric bleeding

b. site of ulcer

Fig. 1: EGD procedure. 


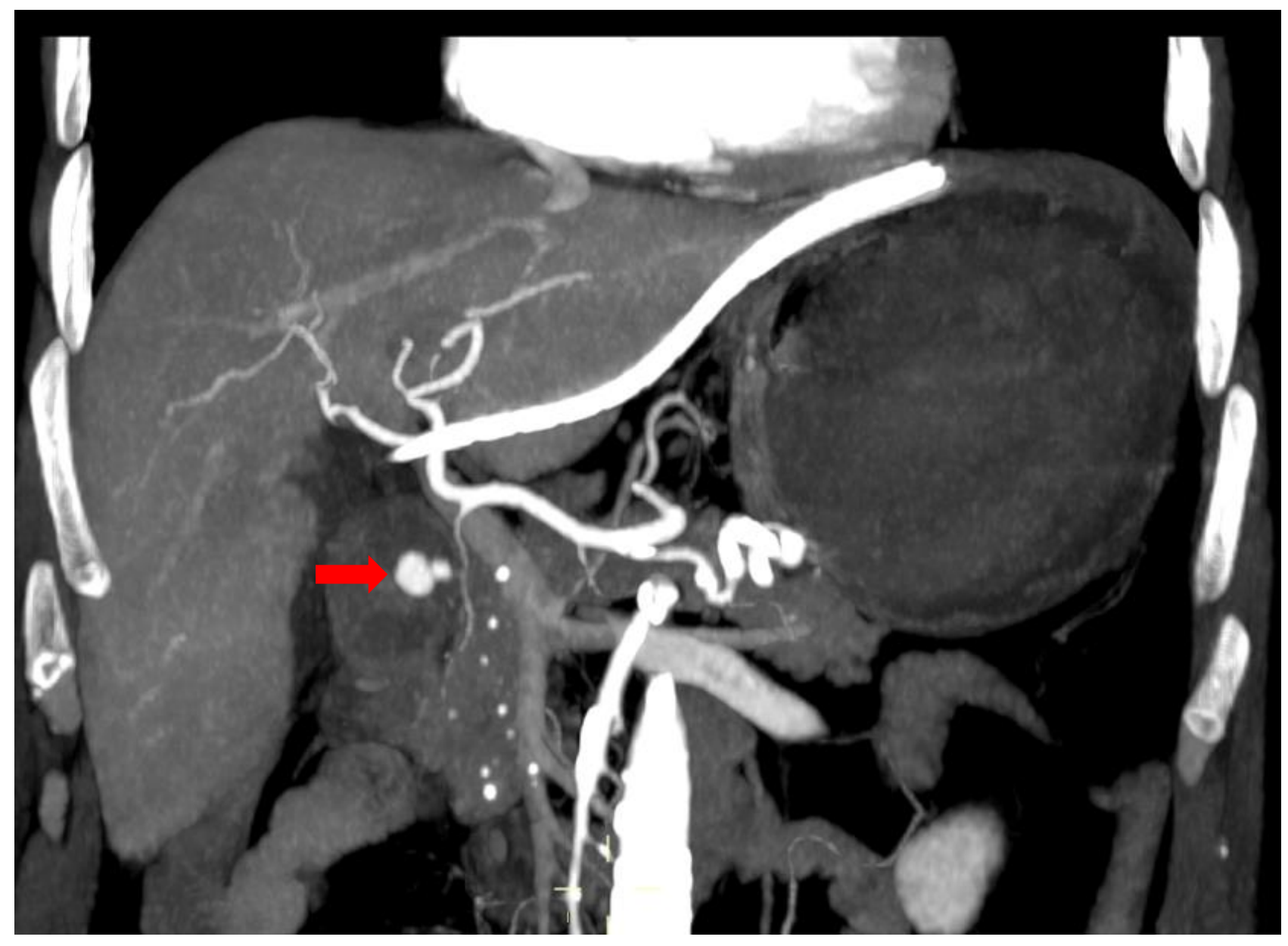

Fig. 2: Abdominal CT showing GDA pseudoaneurysm. 


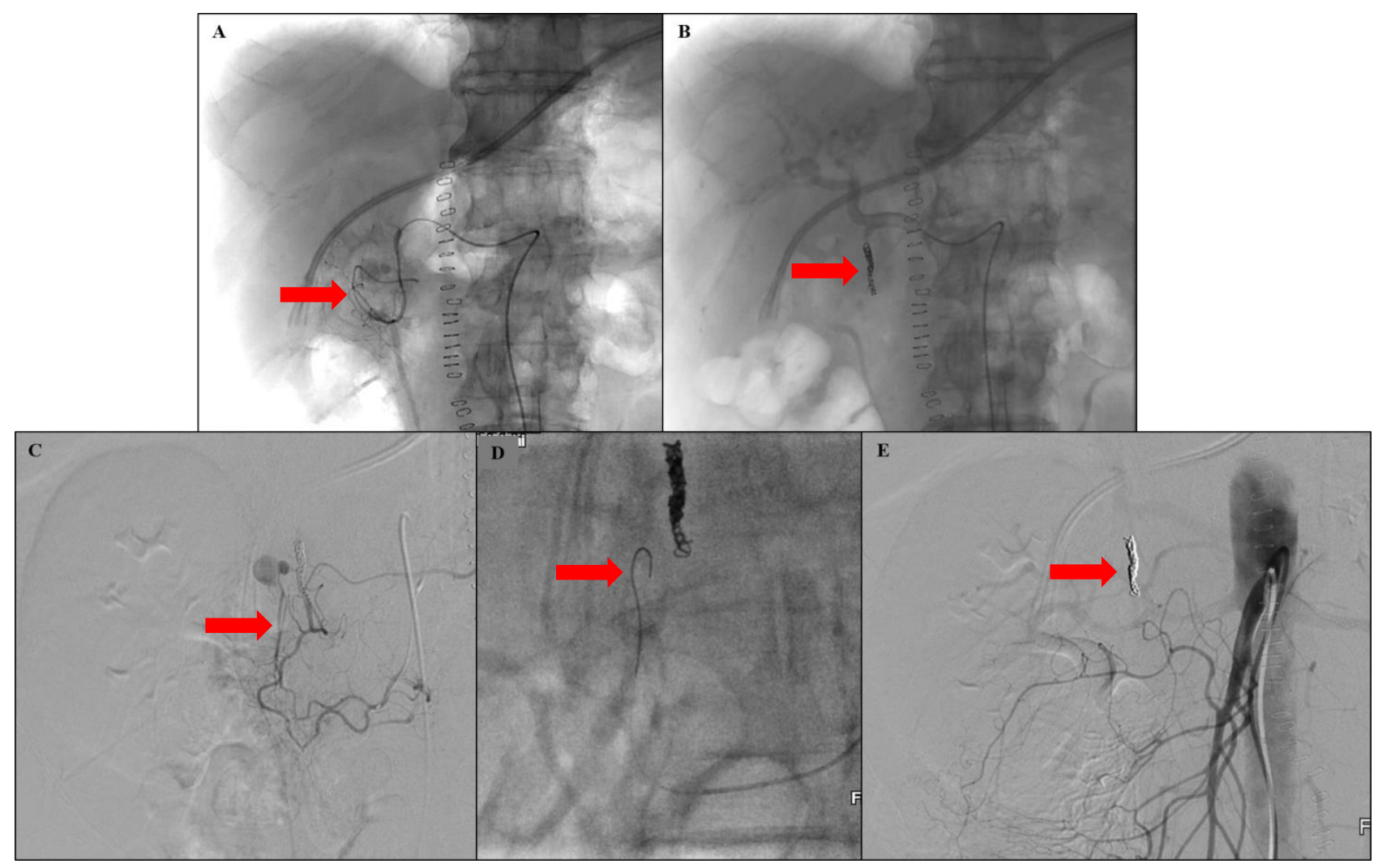

Fig. 3: Selective arteriography of the GDA demonstrated the origin of the pseudoaneurysm (A). Therefore, the GDA was embolized by using micro-coils (B) Angiography performed from the superior mesenteric artery demonstrated a small branch of the inferior pancreatic-duodenal arch feeding the pseudoaneurysm (C), which was dissected by using the micro-guide and micro-catheter (D). The final angiography from the superior mesenteric artery documented the complete exclusion of the pseudoaneurysm from the circulation (E). 


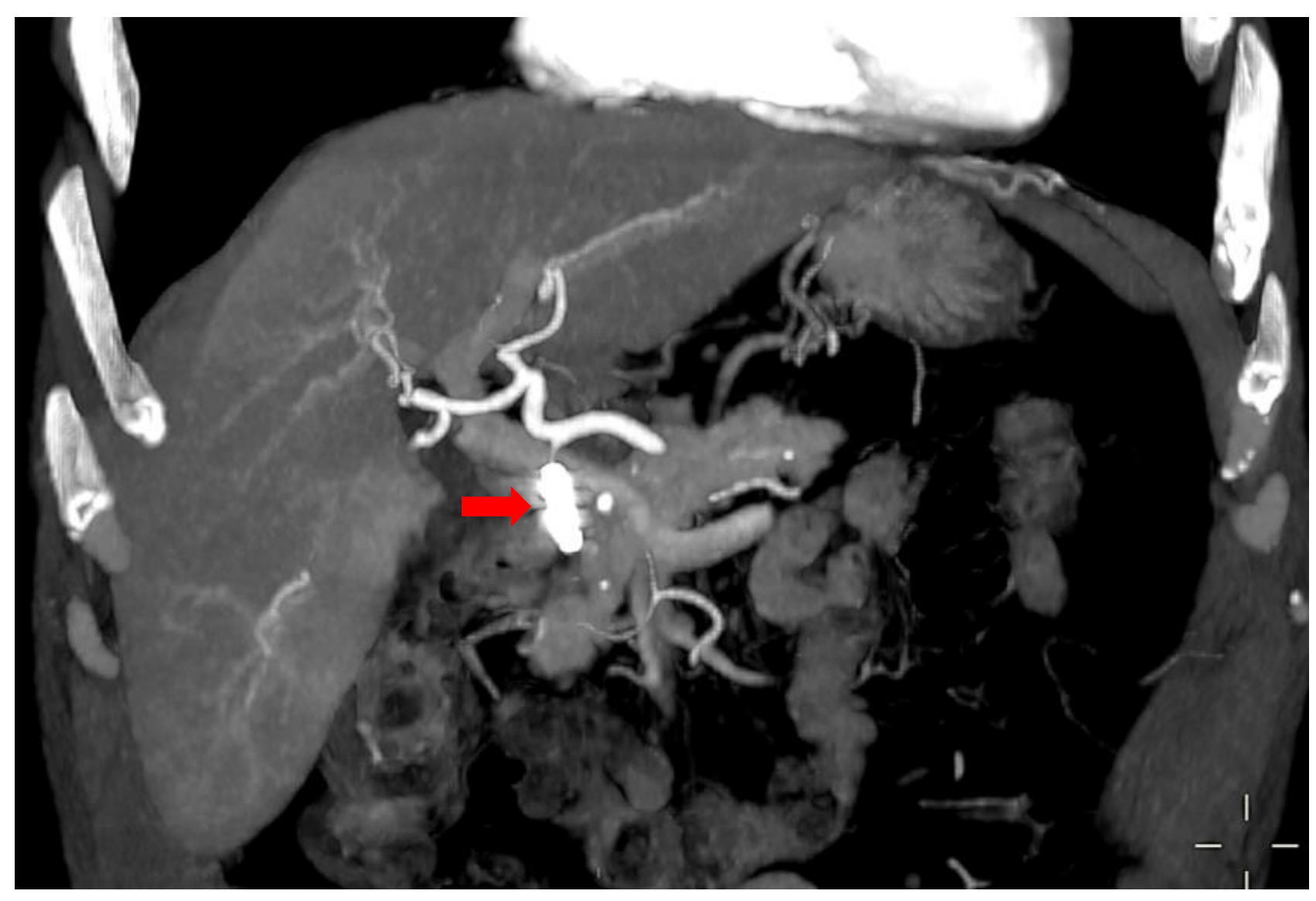

Fig. 4: Abdominal CT showing the absence of the GDA pseudoaneurysm. The micro-coils were correctly positioned in the GDA (red arrow).

\section{Discussion :}

A pseudoaneurysm results from a previous injury affecting the layers of the vasculature. It is also termed "false aneurysm" since the blood remains within the arterial wall (1). Although pseudoaneurysm of the mesenteric vasculature is rare, it requires emergent care due to the risk of rupture that is not related to pseudoaneurysm size (2). Few cases of pseudoaneurysm and true aneurysm of the superior mesenteric artery (3), cœliac trunk (3), cystic artery (4) and right hepatic artery (5) are described in the literature. The splenic artery is the most common artery affected (3). A GDA pseudoaneurysm was present in this case (Figure 5). GDA pseudoaneurysms represent $1.5 \%$ of all visceral pseudoaneurysms (6). Our patient was older than is usually reported in literature (Table 1).

It is important to differentiate between true aneurysm and pseudoaneurysm. True aneurysms depend on vessel abnormalities, whereas pseudoaneurysms are often related to vascular erosion or vascular 
injury (7). Chronic pancreatitis represents one of the most important ætiologies of GDA aneurysm (8). Less frequent causes are vascular abnormalities (9) and trauma (10). Ethanol abuse and peptic ulcer disease are often associated (11). Occasionally, spontaneous GDA pseudoaneurysm occurs (12). In our case report, the patient had a history of active alcoholism and was initially diagnosed with a deep peptic ulcer.

The most frequent clinical presentation of GDA pseudoaneurysm is gastrointestinal bleeding (52\%) and/or abdominal pain (46\%) (13). Though the rupture of the pseudoaneurysm is extremely rare, its mortality rate is $\sim 20-43 \%$ in untreated patients (14). Our patient was admitted to Emergency Department after a first episode of gastrointestinal bleeding due in part to the high risk of rupture.

The two most useful tools for the diagnosis are the abdominal CT scan and visceral arteriography. Arteriography has a higher sensitivity than the CT scan (100\% vs. $67 \%)$ and also can be therapeutic as well as diagnostic (15). Among patients with a diagnosis of pancreatitis, the evidence of a homogeneously enhancing structure next to pseudocyst or vascular structure may suggest the presence of a pseudoaneurysm (16).

The timing of the treatment is crucial, in order to avoid GDA pseudoaneurysm rupture. The optimal approach is still controversial. In the past, surgical approach was the "gold standard" (14), although currently, a non-invasive approach is preferred for stable patients (17). GDA angio-embolization is performed by a transfemoral route with super-selective catheterization of the GDA. Different microcoils are placed proximally and distally to a pseudoaneurysm in order to completely exclude the lesion from the circulation. The procedure is successful if immediate hæmostasis is achieved with no recurrent bleeding up to 48 hours after embolization (18). The embolization success rate is $\sim 79$ $100 \%(\mathbf{1 7}, \mathbf{1 9}-\mathbf{3 9})$, with a possible complication including visceral ischemia (17). In case of embolization failure or for unstable patients, an open surgical approach is preferred, with a variety of procedures available including pseudoaneurysm resection, partial and total gastrectomy, and pancreatectomy (2,

\section{5-17, 25-26,29).}

In summary, GDA pseudoaneurysm, although rare, should be considered among the possible diagnoses in a patient with recurrent acute gastrointestinal bleeding. Due to the risk of rupture, it is essential to 
achieve the diagnosis as soon as possible. A conservative approach with angio-embolization is currently the treatment of choice. 


\begin{tabular}{|c|c|c|c|c|c|c|}
\hline \# & Authors (ref) & $\begin{array}{c}\text { Median } \\
\text { age of } \\
\text { patient }\end{array}$ & Clinical presentation & $\begin{array}{c}\text { First } \\
\text { treatment }\end{array}$ & Type of treatment & $\begin{array}{l}\text { Success of } \\
\text { procedure }\end{array}$ \\
\hline 1 & Gupta et al. (18) & 40 & bleeding & endovascular & $\begin{array}{l}\text { angioembolization/ } \\
\text { thrombin injection }\end{array}$ & yes \\
\hline 2 & $\begin{array}{l}\text { Abdelgabar et al. } \\
\text { (3) }\end{array}$ & 78 & $\begin{array}{c}\text { abdominal pain, vomiting, } \\
\text { bleeding }\end{array}$ & endovascular & angioembolization & yes \\
\hline 3 & Sharma et al. (6) & 28 & acute pancreatitis & endovascular & angioembolization & yes \\
\hline 4 & $\begin{array}{l}\text { Galanakis et al. } \\
\text { (20) }\end{array}$ & 79 & epigastric pain & endovascular & angioembolization & yes \\
\hline 5 & $\begin{array}{c}\text { Giõo Antunes et al. } \\
\text { (13) }\end{array}$ & 54 & epigastric pain, vomiting & - & - & - \\
\hline 6 & $\begin{array}{c}\text { Santos-Rancaño et } \\
\text { al. (21) }\end{array}$ & 48 & hematemesis, melaena & endovascular & angioembolization & yes \\
\hline 7 & Elazary et al. (22) & 18 & recurrent GI bleeding & endovascular & angioembolization & yes \\
\hline 8 & Chong et al. (10) & 48 & acute pancreatitis, melaena & endovascular & angioembolization & yes \\
\hline 9 & $\begin{array}{l}\text { Carrafiello et al. } \\
\qquad(14)\end{array}$ & 69 & acute pancreatisis & endovascular & $\begin{array}{l}\text { angioembolization/ } \\
\text { thrombin injection }\end{array}$ & yes \\
\hline 10 & Geoghegan et & 24 & chronic pancreatisis & endovascular & angioembolization & no \\
\hline
\end{tabular}




\begin{tabular}{|c|c|c|c|c|c|c|}
\hline & al.(23) & & & & & \\
\hline 11 & Klauß et al. (24) & 47 & upper abdominal pain & endovascular & angioembolization & yes \\
\hline 12 & Volpi et al. (25) & 69 & upper GI bleeding & endovascular & angioembolization & yes \\
\hline 13 & Dirks et al. (26) & 59 & recurrent bleeding & endovascular & angioembolization & yes \\
\hline 14 & $\begin{array}{c}\text { Germanos et al. } \\
\text { (27) }\end{array}$ & 49 & chronic pancreatisis & endovascular & angioembolization & yes \\
\hline 15 & $\begin{array}{l}\text { Jovanović et al. } \\
\text { (28) }\end{array}$ & 47 & jaundice & surgical & Billroth II gastrectomy & \\
\hline 16 & Vizsy et al. (29) & 62 & $\begin{array}{c}\text { hematemesis, melaena } \\
\text { jaundice }\end{array}$ & surgical & GDA ligation & $\begin{array}{ll}\text { yes } \\
\text { yes }\end{array}$ \\
\hline 17 & Singh et al. (30) & 35 & $\begin{array}{l}\text { abdominal pain, } \\
\text { hematemesis }\end{array}$ & surgical & GDA ligation & yes \\
\hline 18 & Yen et al. (31) & 43 & jaundice, pruritus & endovascular & angioembolization & yes \\
\hline 19 & Akbari et al. (32) & 88 & epigastric pain & endovascular & angioembolization & yes \\
\hline 20 & $\begin{array}{c}\text { Androulakakis et } \\
\text { al. (33) }\end{array}$ & 77 & abdominal pain, vomiting & - & - & - \\
\hline 21 & Kueper et al. (34) & 60 & abdominal discomfort & endovascular & angioembolization & yes \\
\hline 22 & Lykoudis et al. & 65 & epigastric pain, nausea & endovascular & stent graft & \\
\hline
\end{tabular}




\begin{tabular}{|l|l|l|l|l|l|l|}
\hline 23 & (35) & $\begin{array}{l}\text { Marjanovic et } \\
\text { al.(36) }\end{array}$ & 56 & palpable mass, epigastric & & yes \\
\hline 24 & $\begin{array}{l}\text { piffaretti et al. } \\
\text { (37) }\end{array}$ & 30 & bleeding, hypotension & endovascular & thrombin injection & yes \\
\hline 25 & Savage et al. (38) & 67 & hemorrhagic shock & surgical & surgical resection & yes \\
\hline 26 & Sun et al. (39) & 63 & bleeding & surgical & surgical excision & yes \\
\hline
\end{tabular}

Table 1: GDA pseudoaneurysms described in medical literature. 


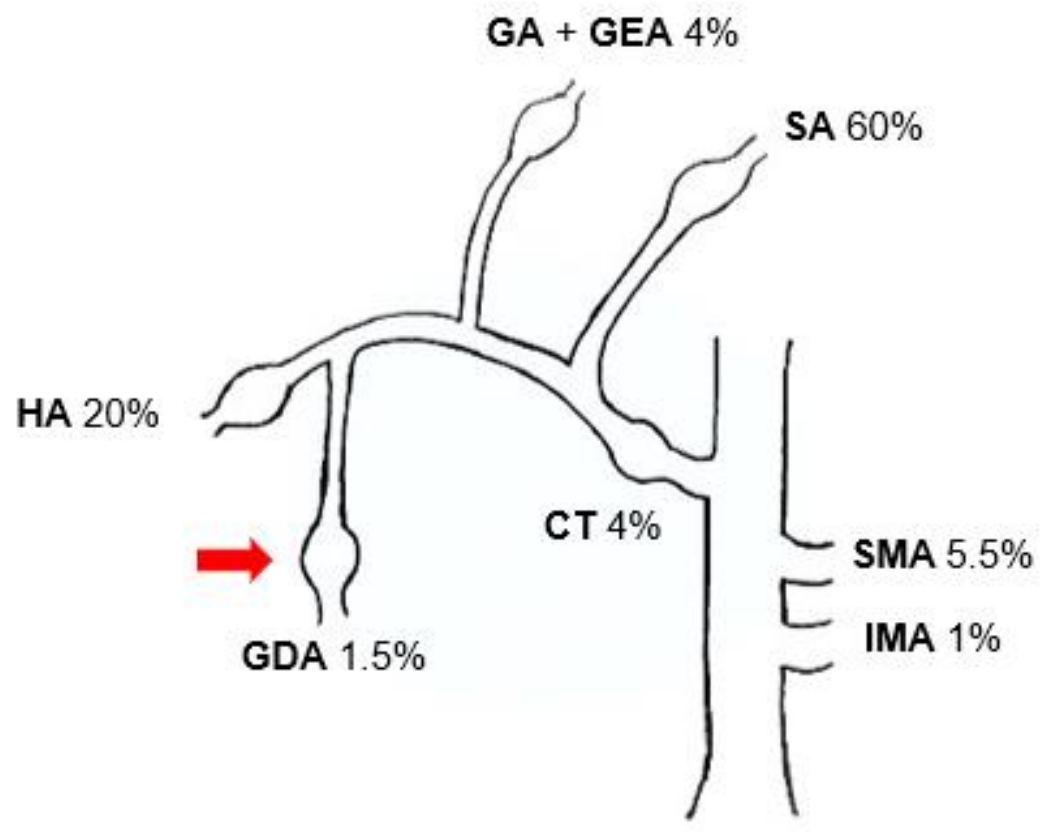

SA = Splenic Artery, SMA = Superior Mesenteric Artery, IMA = Inferior Mesenteric Artery, CT = Celiac Trunk, GDA = Gastroduodenal Artery, HA = Hepatic Arteries, GA + GEA = Gastric + Gastroepiploic Arteries.

Fig. 5: the most common sites of Gl aneurysmal disease.

\section{Key messages:}

- GDA pseudoaneurysm isn't a common diagnosis, but its rupture is a very dangerous complication.

- Clinical presentation is mainly represented by abdominal pain and gastrointestinal bleeding.

- Nowadays for stable patients angio-embolization is considered the treatment of choice.

\section{References:}

1. Awada Z, Al Moussawi H, Alsheikh M, et al. Gastroduodenal Artery Pseudoaneurysm Rupture Post-Billroth II Surgery: Case Report. Cureus. 2019;11:e3833.

2. Matsuno Y, Mori Y, Umeda Y, et al. Surgical repair of true gastroduodenal artery aneurysm: a case report. Vasc Endovascular Surg. 2008;42:497-499. 
3. Abdelgabar A, d'Archambeau O, Maes J, et al. Visceral artery pseudoaneurysms: two case reports and a review of the literature. J Med Case Reports. 2017;11:126.

4. She WH, Tsang S, Poon R, et al. Gastrointestinal bleeding of obscured origin due to cystic artery pseudoaneurysm. Asian J Surg. 2017;40:320-323.

5. Fujio A, Usuda M, Ozawa Y, et al. A case of gastrointestinal bleeding due to right hepatic artery pseudoaneurysm following total remnant pancreatectomy: A case report. Int J Surg Case Rep. 2017;41:434-437.

6. Sharma M, Somani P, Sunkara T, et al. Endoscopic ultrasound-guided coil embolization and thrombin injection of a bleeding gastroduodenal artery pseudoaneurysm. Endoscopy. 2019;51:E36-37.

7. Iyori K, Horigome M, Yumoto S, et al. Aneurysm of the gastroduodenal artery associated with absence of the celiac axis: report of a case. Surg Today. 2004;34:360-362.

8. Bergert $\mathrm{H}$, Hinterseher I, Kersting $\mathrm{S}$, et al. Management and outcome of hemorrhage due to arterial pseudoaneurysms in pancreatitis. Surgery. 2005;137:323-328.

9. Koyazounda A, Jaillot P, Persico J, et al. Aneurysm of the gastroduodenal artery ruptured into the peritoneum. Treatment by embolization. Presse Medicale Paris Fr 1983. 1994;23:661-664.

10. Chong WW, Tan SG, Htoo MM, et al. Endovascular treatment of gastroduodenal artery aneurysm. Asian Cardiovasc Thorac Ann. 2008;16:68-72.

11. Shanley CJ, Shah NL, Messina LM ,et al. Uncommon splanchnic artery aneurysms: pancreaticoduodenal, gastroduodenal, superior mesenteric, inferior mesenteric, and colic. Ann Vasc Surg. 1996;10:506-515.

12. Sethi H, Peddu P, Prachalias A, et al. Selective embolization for bleeding visceral artery pseudoaneurysms in patients with pancreatitis. Hepatobiliary Pancreat Dis Int. 2010;9:634-638.

13. Gião Antunes A, Peixe B, Guerreiro H, et al. Spontaneous thrombosis of a gastroduodenal artery pseudoaneurysm manifesting as a subepithelial lesion. Rev Gastroenterol México Engl Ed. 2018;83:354-356.

14. Carrafiello G, Laganà D, Recaldini $C$, et al. Combined percutaneous thrombin injection and endovascular treatment of gastroduodenal artery pseudoaneurysm (PAGD): case report. Emerg Radiol. 2007;14:51-54. 
15. Habib N, Hassan S, Abdou R, et al. Gastroduodenal artery aneurysm, diagnosis, clinical presentation and management: a concise review. Ann Surg Innov Res. 2013;7:4.

16. Burke JW, Erickson SJ, Kellum CD, et al. Pseudoaneurysms complicating pancreatitis: detection by CT. Radiology. 1986;161:447-450.

17. Kasirajan K, Greenberg RK, Clair D, et al. Endovascular management of visceral artery aneurysm. J Endovasc Ther. 2001;8:150-155.

18. Gupta V, Irrinki S, Sakaray YR, et al. Treatment strategies for bleeding from gastroduodenal artery pseudoaneurysms complicating the course of chronic pancreatitis-A case series of 10 patients. Indian J Gastroenterol Off J Indian Soc Gastroenterol. 2018;37:457-463.

19. Hsu J-T, Yeh C-N, Hung C-F, et al. Management and outcome of bleeding pseudoaneurysm associated with chronic pancreatitis. BMC Gastroenterol. 2006;6:3.

20. Galanakis V. Pseudoaneurysm of the gastroduodenal artery: an unusual cause for hyperamylasaemia. BMJ Case Rep. 2018;2018.

21. Santos-Rancaño R, Antona EM, Montero JVM, et al. A Challenging Case of a Large Gastroduodenal Artery Pseudoaneurysm after Surgery of a Peptic Ulcer. Case Reports in Surgery. 2015;2015:370937.

22. Elazary R, Abu-Gazala M, Schlager A, et al. Therapeutic angiography for giant bleeding gastroduodenal artery pseudoaneurysm. World J Gastroenterol. 2010;16:1670-1672.

23. Geoghegan T, Tuite D, McAuley G, et al. Percutaneous thrombin injection for the treatment of a post-pancreatitis pseudoaneurysm of the gastroduodenal artery. Eur Radiol. 2004;14:2144-2145.

24. Klauß M, Heye T, Stampfl U, et al. Successful arterial embolization of a giant pseudoaneurysm of the gastroduodenal artery secondary to chronic pancreatitis with literature review. J Radiol Case Rep. 2012;6:9-16.

25. Volpi MA, Voliovici E, Pinato F, et al. Pseudoaneurysm of the Gastroduodenal Artery Secondary to Chronic Pancreatitis. Ann Vasc Surg. 2010;24:1136.e7-1136.e11.

26. Dirks K, Schuler A, Lutz $\mathrm{H}$, et al. An unusual cause of gastrointestinal hemorrhage: pseudoaneurysm of the gastroduodenal artery in chronic pancreatitis. Z Gastroenterol. 1999;37:489-493. 
27. Germanos S, Soonawalla Z, Stratopoulos C, et al. Pseudoaneurysm of the Gastroduodenal Artery in Chronic Pancreatitis. J Am Coll Surg. 2009;208:316.

28. Jovanović M, Colović R, Grubov N, et al. Pseudoaneurysm of gastroduodenal artery due to duodenal ulcer causing jaundice and interstitial pancreatitis but not bleeding. Srp Arh Celok Lek. 2004;132:108-111.

29. Vizsy L, Beznicza H, Petoházi A, et al. Successfully operated ruptured gastroduodenal artery pseudoaneurysm. Orv Hetil. 2006;147:1279-1281.

30. Singh O, Gupta SS, Raikwar RS, et al. A rare case of 'Spontaneous rupture of partially thrombosed pseudoaneurysm of gastroduodenal artery associated with chronic pancreatitis'. Indian J Surg. 2009;71:282-283.

31. Yen Y-T, Lai H-W, Lin C-H, et al. Endovascular Salvage for Contained Rupture of Gastroduodenal Artery Aneurysm Presented with Obstructive Jaundice. Ann Vasc Surg. 2015;29:1017.e1-1017.e5.

32. Akbari K, Wood C, Ahmad N, et al. Gastroduodenal artery aneurysm. BMJ Case Rep. 2014;2014.

33. Androulakakis Z, Paspatis G, Hatzidakis A, et al. Gastric outlet obstruction caused by a giant gastroduodenal artery aneurysm: a case report. Eur J Gastroenterol Hepatol. 2001;13:59-61.

34. Kueper MA, Ludescher B, Koenigsrainer I, et al. Successful coil embolization of a ruptured gastroduodenal artery aneurysm. Vasc Endovascular Surg. 2007;41:568-571.

35. Lykoudis PM, Stafyla VK, Koutoulidis V, et al. Stenting of a gastroduodenal artery aneurysm: report of a case. Surg Today.2012;42:72-74.

36. Marjanovic IR, Jevtic M, Misovic S, et al. Endovascular Reconstruction of Giant Gastroduodenal Artery Aneurysm With Stent Graft: Case Report. Vasc Endovascular Surg. 2010;44:392-394.

37. Piffaretti G, Tozzi M, Carrafiello G, et al. A case of gastroduodenal artery aneurysm in a HIVpositive patient treated by combined percutaneous thrombin injection and endovascular coil embolization. J Cardiovasc Surg. 2008;49:659-661.

38. Savage J, Hsee L. Spontaneous gastroduodenal artery aneurysm rupture in acute surgery. $\mathbf{N} \mathbf{Z}$ Med J. 2012;125:155-157.

39. Sun MS, Wang HP, Lin JT . Gastroduodenal artery aneurysm mimicking a bleeding submucosal tumor. Gastrointest Endosc. 2001;54:621. 